\title{
Performance Evaluation of Quality of Service (QoS) based Web Service Selection Methods for Healthcare Product Shopping Domain Using Analysis of Variance (ANOVA)
}

Maheswari S ( $\nabla$ smbrrksrkd2011@gmail.com )

National Engineering College

\section{Pitchai R}

B V Raju Institute of Technology

\section{Supraja P}

SRM Institute of Science and Technology

\section{Babu S}

SRM Institute of Science and Technology

\section{Research Article}

Keywords: QoS, Analytical Hierarchical preparing, Logical Scoring Preference, Fuzzy Topsis, ANOVA, Health care product shopping domain.

Posted Date: March 17th, 2021

DOI: https://doi.org/10.21203/rs.3.rs-266535/v1

License: (9) This work is licensed under a Creative Commons Attribution 4.0 International License.

Read Full License 


\title{
Performance Evaluation of Quality of Service (QoS) based Web Service Selection Methods for Healthcare Product Shopping Domain using Analysis of Variance (ANOVA)
}

\author{
${ }^{1}$ Maheswari S, Pitchai $\mathbf{R}^{2}$, Supraja $\mathbf{P}^{3}$, Babu $\mathbf{S}^{4}$ \\ ${ }^{1}$ Department of Computer Science and Engineering, National Engineering College, Kovilpatti-623501, India. \\ ${ }^{2}$ Department of Computer Science and Engineering, B V Raju Institute of Technology, Narsapur, Telangana, India. \\ ${ }^{3,4}$ School of Computing, SRM Institute of Science and Technology, Kattankulathur, India \\ smbrrksrkd2011@gmail.com¹, pitchrks1984@gmail.com², p.supraja18@gmail.com³, babubalaji2k5@gmail.com ${ }^{4}$
}

\begin{abstract}
Guaranteeing Quality of Service (QoS) concerning web administrations is the capacity to respond to the necessities and comprehend the prerequisites according to the tendencies of a client. It is resolved subject to the nonpractical properties of the web administrations. Dependent upon the conditions, administrations clients may have an extent of tendencies for the non utilitarian principles. This made a way for different QoS based web administrations assurance segments which along these lines require an evaluation plot for grasping a particular methodology. Investigation of change is a particular kind of verifiable hypothesis testing used for making decisions using data. The goal of the paper is to dismember the plans specifically Analytical Hierarchical preparing (AHP), Logical Scoring Preference (LSP) and Fuzzy Topsis reliant on extent of customer tendency norms and investigate them using Analysis of Variance (ANOVA). QWS dataset has been used for exploring recently referenced three plans. Preliminary outcomes show that the Fuzzy Topsis contrive beats the other web organization assurance techniques.
\end{abstract}

Keywords--- QoS; Analytical Hierarchical preparing; Logical Scoring Preference; Fuzzy Topsis; ANOVA; Health care product shopping domain.

\section{INTRODUCTION}

With the improvement of number of administrations over the Internet, it is astounding to pick sensible web administrations among the distinctive web administrations which give similar functionalities proposed by [1]. Nonpractical standards are utilized for productive choice in a space. The ability to offer better types of assistance is given by Quality of Service (QoS) [21]. While there are various structures available to pick the administrations with the most imperative QoS score [21], the truth of building a model which takes in the customer's assessing of an assistance as a huge commitment for assurance is less idea of. The key necessities are QoS limits, Customer administrations essential, and Service commitments by the master association. This paper considers the QoS boundaries, for example, reaction time, dependability, adaptability, notoriety, throughput and accessibility, openness and cost.

There are two normalization techniques are available expected for normalize the QoS regards. Two strategies are Distance based Normalization and Proportion based Normalization. Separation based standardization procedure masterminded into two methodologies are Linear Normalization and Vector Normalization. Extent Based Normalization procedure is Max-Min Normalization. In this paper considers three assistance determination calculations [7] are Analytic Hierarchic Process (AHP), Logical Scoring Preference with Ordered Weighted 
Averaging (LSP with OWA) and Fuzzy with Technique for Order Preference by Similarity to an ideal Solution (Topsis).AHP is used for Linear Normalization, LSP with OWA is used for Max-Min Normalization and Fuzzy Topsis using Vector Normalization. The AHP technique considers an arrangement of study guidelines and assorted decision among which the most ideal decision is to be made by the customer tendencies. It creates a heap for every assessment models; it's vital factor concerning the customer's pair adroit connections of the factors.

The LSP method uses OWA Operator for web administration determination. These OWA regards are utilized in the figuring of LSP which continuously helps with situating the administration determination and maintained the situation of each assist we with choosing the most elevated level assistance in light of the fact that the best one. The system for Order Preference by Similarity to an ideal Solution (Topsis) to help administration clients and providers to inspect open web administration determination with fluffy sentiments.

\section{Linear normalization:}

In Linear normalization, the weights are assigned directly based on consumer preferences.

Minimizing Maximizing

$$
\operatorname{Norm}\left(q_{i, j}\right)=q_{i, j \min } / q_{i, j} \quad \operatorname{Norm}\left(q_{i, j}\right)=q_{i, j} / q_{i, j m a x}
$$

\section{Vector normalization:}

In vector normalization, the weights are allocated dependent on reviews chiefs' insight.

Minimizing $\operatorname{Norm}\left(q_{i, j}\right)=q_{i, j} / q_{i, j} \sqrt{\sum_{i=1}^{m}\left(q_{i, j}^{2}\right)}$ Maximizing $\operatorname{Norm}\left(q_{i, j}\right)=1 / q_{i, j} \sqrt{\sum_{i=1}^{m} \frac{1}{q_{i, j}^{2}}}$

\section{Max-Min normalization:}

In Max-Min normalization weights are assigned supported user preferences. There are two processes to be considered and that they are maximization and minimization. If the user wishes to normalize the parameter like interval and price, then minimization is taken into account or if the user wants to normalize the parameters like Accessibility, Availability, Reliability, Reputation, Scalability and Throughput, then maximization is taken into account for service selection.

$\operatorname{MinimizingNorm}\left(\mathrm{q}_{-}(\mathrm{i}, \mathrm{j})\right)=\left(\mathrm{q} \_(\mathrm{i}, \mathrm{j})-\mathrm{q}_{-}(\mathrm{i}, \mathrm{jmin})\right) /\left(\mathrm{q} \_(\mathrm{i}, \mathrm{jmax})-\mathrm{q}_{-}(\mathrm{i}, \mathrm{jmin})\right)$

$\operatorname{MaximizingNorm}\left(\mathrm{q}_{-}(\mathrm{i}, \mathrm{j})\right)=\left(\mathrm{q} \_(\mathrm{i}, \mathrm{jmax})-\mathrm{q} \_(\mathrm{i}, \mathrm{j})\right) /\left(\mathrm{q} \_(\mathrm{i}, \mathrm{jmax})-\mathrm{q} \_(\mathrm{i}, \mathrm{jmin})\right)(3)$

Where,

$q i, j=$ the value of ith service and $j$ th parameter, qi,jmin = the minimum value of $j$ th parameter of the ith service, qi,jmax $=$ the utmost value of jth parameter of the ith service

The goal is to analyze the various strategies for improving the QoS based methodology. To assess the service process, an analogous examination is formed keen about three Selection strategies. Testing strategies for Analysis of Variance (ANOVA) device is conversant in lengthen the exhibition of each one in every of these normalization methods. 
The correlation is performed so just one normalization method are often followed and therefore the result yields best web service to the service consumer. A statistical methodology is finished and that they are talked about in area 5. The reminder of the paper consists as follows: area 2 examines related work, segment 3 talks about the service selection methods, and segment 4 presents the exploratory outcomes and Section 6 concludes the paper.

\section{RELATED WORK}

[1], [2], [3], [10] and [23] proposed match making algorithm, it described using Inputs, Outputs, Pre-conditions and Effects. The proposed techniques discovery the of relevant web services and also finding the relation between the concepts.[8],[23] and [21] discussed QoS-based selection of best web service considering users preferences by using normalization technique and the services are ranked based on the scores of each service. The analysis is made so that the optimal service is retrieved based on the user's constraint values of each of the quality attribute. The services that are redundant are eliminated from those that are relevant. [5] Proposed a service selection based on service providers.

[11] Proposes a methodology for planning and creating QoS metaphysics and its QoS-based positioning calculation for assessing Web administrations. It utilizes QoS metaphysics for communicating QoS data and requirements and an AHP-based positioning calculation for Web administration determination. [6],[9] proposed LSP based web administration selection.[4],[12] proposed the Fuzzy Topsis technique is utilized to tackle the web administration choice issue when a gathering of clients have various assessments on assessment. [22] Discussed the aftereffects of two conventional examinations that researched Web Usability estimation utilizing t-test. This test used to says invalid theory or substitute speculation. In this paper utilize same speculation test utilizing ANOVA and T-test for matched methods was led to see which calculations are similarly acceptable. This paper utilize same ANOVA test for web administration choice calculation.

\section{Semantic web service selection Framework}

In this paper considers the Health care item space web administration determination strategies. Web based shopping offers immense comfort so individuals are getting a charge out of it. In the event that you purchase emergency clinic and on the web, it will save your time that you would have spent wandering around your city searching for a specific inventory from the nearby clinical stores. Visiting different stores is baffling other than being tedious. So purchasing clinical items online will assist you with setting aside cash. Viable retailing requires executing an assortment of strategies to stand out enough to be noticed of your purchaser so you help them deal with squeezing medical care needs while empowering client dedication.

The target of the Framework is to choose the best technique. The Health care product shopping domain Semantic Web Service Selection Framework is shown in Figure.2.

Where, $S_{P}$ - service provider, $C_{R}$ - Service consumer, $S_{R}$ - service repository, $R_{R}$ - Retrieved result, $S_{S}-$ Health care product shopping Service selection Methods 


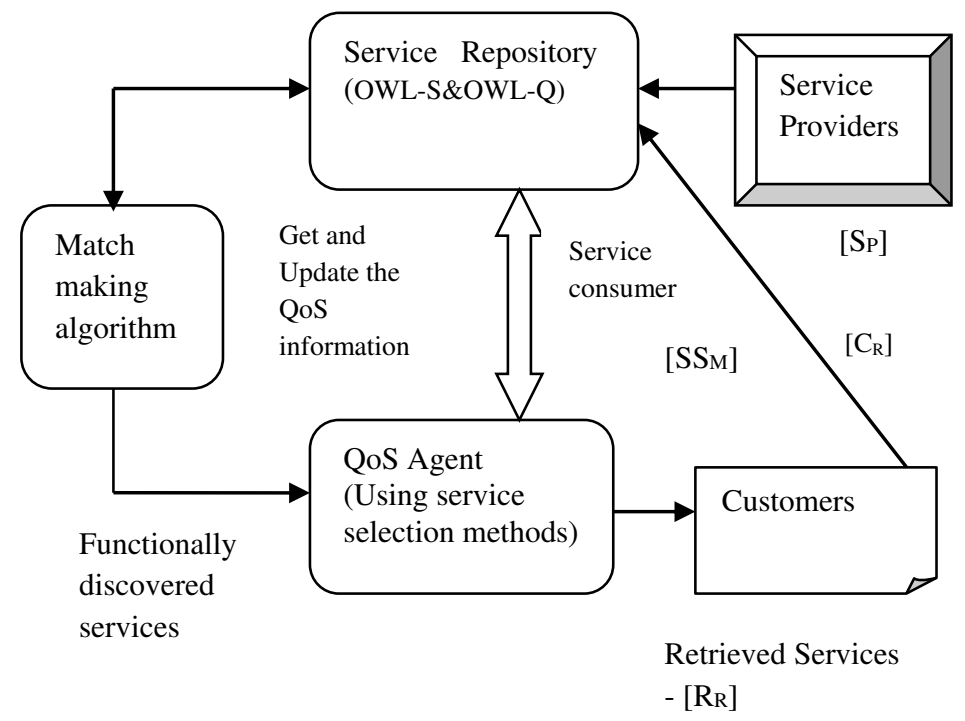

Figure 2: Semantic Web Service Selection Framework

The target of the selection process is to choose best online shoppinf web service from the accessible service. The Process of web service choice appeared in Figure 2 includes the cooperation among service archive, Service supplier and Service buyer.

The service portrayals in the archive incorporate info and yield boundaries, service profile and establishing data with Quality of service esteems. The service mentioned by the shopper is contrasted and the accessible services in the archive. Matchmaking is liable for disclosure of significant web services dependent on Input, Output, Precondition and impact. At the point when a few practically comparable administrations are discovered, they are positioned dependent on non-useful boundaries by utilizing services choice techniques. In light of the position, a productive Web services that fulfills the client's prerequisites is chosen. QoS Agent answerable for the choice of appropriate web services based are to be specific Response time, Throughput, Reputation, Scalability, Reliability, Availability, Accessibility and Cost. The QoS Agent refreshes the information base with the positions of administrations and it send the most significant support of the services customer. Services choice strategies are as per the following.

\section{A. Web Service Selection Using AHP Method:}

Analytic hierarchy process is a procedure for procedure complex decision using multi criterion decision making. It assists with finding the best arrangement that suits the objective and inclination. From AHP(19), the issue is decomposed into progressive system of sub issues which can be tackled freely and weight is allocated to each sub issue in the chain of importance. By doling out weight, the examination should be possible among various and an unbalanced component in a reliable manner. AHP order has its fundamental attribute of organizing the administrations dependent on the shopper needs. In AHP the consumers are allowed to specify several options for 
selection criteria. Based on the specified criteria AHP takes decision for deciding the best services. Analytic hierarchy process can be performed using the following steps:

\section{Step 1 : Parameters Decomposition}

The initial step is to structure a choice issue and choice standards. The unpredictable choice issue is decayed into its constituent parts and a progressive system is framed (group1: Performance factor, group 2: Dependability factor, group 3: Security factor, group4: Business factor). Let us expect that there are M web services and N QoS standards. Let us take five web services and eight QoS boundaries. Accordingly, $\mathrm{M}=5$ and $\mathrm{N}=8$. The eight QoS boundaries are, for example, Response time, Throughput, Reliability, Scalability, Availability, Accessibility, Reputation, and Cost.

\section{Step 2 : Consumer Based Weight Assignment}

The next step is to set the priority of the criteria. Maximum weight is given to the QoS criteria which the consumer prefers. Least weight is given to other QoS criteria.

Table 1: Consumer preference for response time

\begin{tabular}{|c|c|c|c|c|c|c|c|}
\hline Response Time & Throughput & Reliability & Scalability & Availability & Accessibility & Reputation & Cost \\
\hline 0.8 & 0.2 & 0.3 & 0.3 & 0.3 & 0.1 & 1 & 1 \\
\hline
\end{tabular}

In the above Table 1, response time takes the highest weight because it is preferred by the consumer.

\section{Step $3 \quad$ : Linear Normalization}

The web services (WS1...WS5) and the eight QoS parameters (Q1... Q8) are shown in the following Table 2:

Table 2: Web services and QoS parameters

\begin{tabular}{|l|l|l|l|l|l|l|l|l|}
\hline & Q1 & Q2 & Q3 & Q4 & Q5 & Q6 & Q7 & Q8 \\
\hline WS1 & 350 & 8 & 72 & 0.89 & 90 & 80 & 89 & 3200 \\
\hline WS2 & 495 & 19 & 75 & 0.88 & 87 & 76 & 89 & 4300 \\
\hline WS3 & 310 & 1.6 & 80 & 0.95 & 98 & 97 & 88 & 2100 \\
\hline WS4 & 3335 & 1.6 & 78 & 0.89 & 90 & 80 & 85 & 10050 \\
\hline WS5 & 300 & 1.3 & 67 & 0.92 & 99 & 99 & 86 & 3200 \\
\hline
\end{tabular}

The next step is to normalize the values shown in above Table 3. Linear normalization is performed using the Equation (1) .Norm $(300)=300 / 350=0.85$. Similarly, other values are calculated.

Table 3: Result of linear normalization

\begin{tabular}{|l|l|l|l|l|l|l|l|l|}
\hline & Q1 & Q2 & Q3 & Q4 & Q5 & Q6 & Q7 & Q8 \\
\hline WS1 & 0.85810 & 0.42286 & 0.99730 & 0.95417 & 0.91616 & 0.82712 & 0.99963 & 0.68 \\
\hline WS2 & 0.53678 & 1.00011 & 0.96980 & 0.91534 & 0.91823 & 0.84450 & 1.005410 & 0.6000 \\
\hline WS3 & 0.99066 & 0.09367 & 0.98570 & 1.00034 & 0.99314 & 0.94829 & 0.99541 & 1.2800 \\
\hline WS4 & 0.08565 & 0.09105 & 1.05400 & 0.95814 & 0.91615 & 0.85712 & 0.98308 & 0.3000 \\
\hline
\end{tabular}




\begin{tabular}{|l|l|l|l|l|l|l|l|l|}
\hline WS5 & 1.05100 & 0.08857 & 0.93960 & 0.98562 & 1.31000 & 1.00560 & 0.97680 & 0.68 \\
\hline
\end{tabular}

\section{Step $4 \quad$ : Formation of Pair Wise Comparison Matrix}

The subsequent stage is to perform pair wise comparison. The pair wise comparison is performed for each QoS models. The pair savvy framework (B) is a M x M lattice. All the slanting estimations of the matrix are one. In the event that every passage of the matrix bih>1, at that point I rules is superior to $\mathrm{h}$ models. On the off chance that passage of the matrix bih $<1$, at that point $\mathrm{i}$ criteria is more terrible than $\mathrm{h}$ criteria. The pair wise matrix of Q1 ((response time) is appeared in underneath Table 4:

Table 4: Pair wise comparison matrix for response time

\begin{tabular}{|l|l|l|l|l|l|}
\hline & WS1 & WS2 & WS3 & WS4 & WS5 \\
\hline WS1 & 1.025000 & 1.75997 & 0.86667 & 10.7120 & 0.92010 \\
\hline WS2 & 1.51966 & 1.00320 & 0.53608 & 7.43650 & 0.64891 \\
\hline WS3 & 1.26590 & 1.97649 & 1.00000 & 13.0215 & 0.99705 \\
\hline WS4 & 0.09422 & 0.16705 & 0.07828 & 1.03600 & 0.08913 \\
\hline WS5 & 1.28686 & 1.80487 & 1.01960 & 12.7041 & 1.00500 \\
\hline
\end{tabular}

$\mathrm{B}(1,1)=0.85 / 0.85=1 . \mathrm{B}(1,2)=0.85 / 0.536=1.5$. Similarly, other values are computed

\section{Step 5 : Different Combination of Score Matrix}

The next step is to find the score matrix for each web service. The score matrix $(\mathrm{S})$ is obtained as expression Equation (7).

The subsequent stage is to discover the score grid for each web administration. The score lattice (S) is gotten as articulation Equation

$$
\mathrm{S}=\left[\begin{array}{lll}
\mathrm{s}^{1} \ldots \ldots & \mathrm{s}^{\mathrm{m}}
\end{array}\right]
$$

It is found by adding all entries in a column and taking its reciprocal. The score matrix of response time is shown in the following Table 5.

Table 5: Score matrix for response time

\begin{tabular}{|l|l|l|l|l|l|}
\hline & WS1 & WS2 & WS3 & WS4 & WS5 \\
\hline Score & 0.250673 & 0.2513 & 0.295661 & 0.03236 & 0.31126 \\
\hline
\end{tabular}

Score $($ WS1 $)=1 /(1.5+1.2+0.094+1.28)=0.250673$. Similarly, the other values are calculated

\section{Step $6 \quad$ Weight Based Overall Score Matrix}

The following stage is to consolidate the score matrix with the weights to locate the general score. The general score of the primary chain of command is found by multiplying the score estimations of Response time and Throughput with weights in Table 1.Overall score of response time and throughput $=(0.250673 * 0.8)+(0.19474 *$ $0.2)=0.20000$. The general score of response time and throughput is appeared in Table 6 . 
Table 6: Overall score for response time \& throughput

\begin{tabular}{|l|l|l|l|l|l|}
\hline & WS1 & WS2 & WS3 & WS4 & WS5 \\
\hline Score & 0.20012 & 0.15560 & 0.28143 & 0.064720 & 0.25610 \\
\hline
\end{tabular}

Similarly the overall score of criteria in other hierarchy is found.

After finding the overall score the values in the hierarchy are combined and it is listed as follows Table 8 . The first hierarchy (response time \& throughput) and the second hierarchy (scalability, availability, accessibility and reliability) are combined and listed in Table 7.

$0.20012+0.155=0.3512$

Table 7: Group 1 and 2: AHP values of web services

\begin{tabular}{|l|l|l|l|l|l|}
\hline & WS1 & WS2 & WS3 & WS4 & WS5 \\
\hline Value & 0.3512 & 0.6202 & 0.5335 & 0.278 & 0.3571 \\
\hline
\end{tabular}

Table 8: Final AHP score table

\begin{tabular}{|l|l|l|l|l|l|}
\hline & WS1 & WS2 & WS3 & WS4 & WS5 \\
\hline Value & 0.9812 & 0.86571 & 0.99650 & 0.66505 & 0.920132 \\
\hline
\end{tabular}

\section{Step $7 \quad$ Web Service Ranking}

The Table 9 shows the ranking of web services

Table 9: Ranking of web services

\begin{tabular}{|l|l|c|}
\hline Rank & Web Service & Value \\
\hline 1 & WS3 & 0.99650 \\
\hline 2 & WS1 & 0.9812 \\
\hline 3 & WS5 & 0.920132 \\
\hline 4 & WS2 & 0.86571 \\
\hline 5 & WS4 & 0.66505 \\
\hline
\end{tabular}

\section{B. $\quad$ Web Service Selection Using LSP Method:}

Logical Scoring Preference strategy is utilized for Max-min normalization procedure. The connection between criteria, for example, simultaneity (conjunction) and replaceability (disjunction) is considered for Web Service choice.

Simultaneity: For example, A health care product purchaser says that they at the same time need great throughput and a good response time with throughput being a higher priority than response time. All things considered, we have to give equivalent priority to both the boundaries

Replaceability: The rules (throughput and response time) can supplant one another. For instance: A lower throughput is worthy if the response time is acceptable. LSP is basically used to address the idea of replaceability which will be extremely valuable in regions where we consider n number of QoS factors in discovering a proficient help.

\section{Step $1 \quad$ : $\quad$ Perform Max-Min Normalization}


This step is to perform Max-Min normalization of the values shown in Table 11. The following normalization Equation (3) are used to normalize the values:

Consideration of Table $(2,10)$ the normalized value of each service is calculated. There are two cases to be considered:

Case 1(minimum normalization): The user wishes to minimize the Response time (Q1) and cost (Q8) of web services. Equation 8 is used for minimization process. The process of minimization is shown below:

$$
\operatorname{Norm}(350)=\frac{(3335-350)}{(3335-300)}=0.9835
$$

Case 2 (Maximum Normalization): In this case, the parameters to be considered are Throughput (Q2), Reliability (Q3), Scalability (Q4), Reputation (Q5),Availability (Q6), Accessibility (Q7), and. Equation 9 is used for maximization process. The process of maximization is shown in Table 10:

Table 10: User preferred weights (Maximization)

\begin{tabular}{|l|l|l|l|l|l|l|l|l|}
\hline QoS Parameter & Q1 & Q2 & Q3 & Q4 & Q5 & Q6 & Q7 & Q8 \\
\hline Weight & 0.8 & 0.02 & 0.02 & 0.02 & 0.02 & 0.02 & 0.05 & 0.05 \\
\hline
\end{tabular}

$$
\operatorname{Norm}(8)=\frac{8-1.3}{19-1.3}=0.37
$$

From this calculation, all the normalized values are calculated and it is shown in the following Table 11:

Table 11: Max-Min normalization values

\begin{tabular}{|l|l|l|l|l|l|l|l|l|}
\hline & Q1 & Q2 & Q3 & Q4 & Q5 & Q6 & Q7 & Q8 \\
\hline WS1 & 0.983 & 0.37 & 0.94 & 0.38 & 0.35 & 0.19 & 0.85 & 0.963 \\
\hline WS2 & 0.95 & 1.00 & 0.60 & 0.02 & 0.02 & 0.000 & 1.001 & 0.84 \\
\hline WS3 & 0.998 & 0.008 & 0.60 & 1.03 & 0.88 & 0.89 & 0.61 & 1.000 \\
\hline WS4 & 0.01 & 0.009 & 1.01 & 0.38 & 0.34 & 0.18 & 0.000 & 0.0021 \\
\hline WS5 & 1.02 & 0.01 & 0.01 & 0.79 & 1.02 & 1.01 & 0.42 & 0.824 \\
\hline
\end{tabular}

\section{Step $2 \quad$ : Calculation of Evaluation Function (Es)}

$\mathrm{E}_{\mathrm{s}}=1-\frac{\mathrm{V}_{\mathrm{x}}-\mathrm{V}_{\mathrm{i}}}{\mathrm{V}_{\mathrm{x}}-\mathrm{V}_{\mathrm{n}}}$ iff $\mathrm{w} \geq 0$

Where, $\mathrm{Vx}$ is the most extreme estimation of all important services in a single measure and Vnis the base worth and Viis the current help esteem. The Es esteem is determined from the normalized qualities appeared in Table 11 and Equation (10). The service with the higher Es esteem is considered for the following cycle. The above recipe is applied just when the heaviness of a help is more prominent than 0 .

Let $\mathrm{Vx}=1.0, \mathrm{Vi}=0.98, \mathrm{Vn}=0.00$, then

$$
\text { Es }=1-\left(\frac{(1.00-0.98)}{(1.00-0.00)}\right)=0.98
$$


The Equation (11) if for calculating Es value for the services which has the weights less than 0.

$E_{s}=\frac{v_{x}-V_{i}}{V_{x}-V_{n}}$ iff $w<0$

From the set of Equations of (10) and (11) the value of the evaluation function is calculated and it is shown in Table 12. The table 11 is given as input for calculating the logical score.

Table 12: Evaluation function value

\begin{tabular}{|l|l|l|l|l|l|l|l|l|}
\hline & $Q 1$ & $Q 2$ & $Q 3$ & $Q 4$ & $Q 5$ & $Q 6$ & $Q 7$ & $Q 8$ \\
\hline WS1 & 0.98 & 0.36 & 0.84 & 0.37 & 0.31 & 0.17 & 0.8 & 0.875 \\
\hline WS2 & 0.92 & 1.00 & 0.50 & 0.00 & 0.00 & 0.00 & 1.00 & 0.75 \\
\hline WS3 & 0.99 & 0.006 & 0.50 & 1.00 & 0.85 & 0.87 & 0.60 & 1.00 \\
\hline WS4 & 0.00 & 0.006 & 1.0 & 0.37 & 0.31 & 0.17 & 0.00 & 0.00 \\
\hline WS5 & 1.00 & 0.00 & 0.00 & 0.78 & 1.0 & 1.0 & 0.40 & 0.875 \\
\hline
\end{tabular}

\section{Step $3 \quad$ : The LSP Value Calculation}

The score is calculated based on the following Equation (12)

$\mathrm{L}=\left(\left|\mathrm{w}_{1}\right| \mathrm{E}_{1}{ }^{\mathrm{r}}+\left|\mathrm{w}_{2}\right| \mathrm{E}_{2}{ }^{\mathrm{r}}+\left|\mathrm{w}_{3}\right| \mathrm{E}_{3}{ }^{\mathrm{r}}+\cdots+\left|\mathrm{w}_{\mathrm{n}}\right| \mathrm{E}_{\mathrm{n}}{ }^{\mathrm{r}}\right)^{\frac{1}{\mathrm{r}}}$

where $\mathrm{L} \leftarrow$ relevant web services rank.

$\mathrm{r} \leftarrow$ Logic relation

Weighting Parameter $=\sum_{\mathrm{i}=1}^{\mathrm{n}}\left|\mathrm{w}_{\mathrm{i}}\right|=1$

Weighting Parameter $=0.8+0.02+0.02+0.02+0.02+0.02+0.05+0.05=1$

It shows that the summation of all weights specified by the user should be equal to one.

\section{Step $4 \quad$ : Ordered Weighting Average}

Requested Weighting Average is cycle of discovering rank of the specific boundary which incorporates the OWA(r) is ORNESS degree, $\mathrm{n}$ is the quantity of QoS boundaries, $\mathrm{w}_{-}$jis weight of every model and the recipe for ascertaining OWA is demonstrated as follows.

$$
\begin{aligned}
& \operatorname{Orness}(\text { OWA })=\frac{1}{n-1} \sum_{j=0}^{n}(n-j) w_{j} \\
& \begin{aligned}
\text { Orness }(O W A)= & \frac{1}{8-1} \sum_{j=1}^{8}(8-j) w_{j} \\
\text { Orness }(O W A)= & \frac{1}{8-1}[((8-0.983) * 0.8)+((8-0.37) * 0.02)+((8-0.94) * 0.03)+((8-0.38) * 0.03) \\
& +((8-0.35) * 0.03)+((8-0.19) * 0.03)+((8-0.85) * 0.03)+((8-0.963) * 0.03)] \\
& =1.014
\end{aligned}
\end{aligned}
$$

\begin{tabular}{|c|c|}
\hline Value of ORNESS degree (L) & Rank value \\
\hline $\mathrm{L}<0.333$ & 0 \\
\hline $\mathrm{L}<0.3750$ & 0.2 \\
\hline
\end{tabular}

The following Table 13 shows the orness value and the rank:

Table 13: Orness degree based rank asignment 


\begin{tabular}{|l|l|}
\hline $0.3750 \leq \mathrm{L}<0.4375$ & 0.5 \\
\hline $0.4375 \leq \mathrm{L}<0.5$ & 1.0 \\
\hline $0.5 \leq \mathrm{L}<0.5625$ & 1.5 \\
\hline $0.5625 \leq \mathrm{L}<0.6232$ & 2.0 \\
\hline $0.6232 \leq \mathrm{L}<0.6250$ & 2.3 \\
\hline $0.6250 \leq \mathrm{L}$ & 3.0 \\
\hline
\end{tabular}

The rank of the service is calculated using orness value. The above Table 13 shows the orness value and the rank. From the above table 13 the concluded $\mathrm{r}$ value for web service 1 is 3 . Similarly The LSP value is calculated for all other services using Equation 12 and that is listed in Table 14.

$$
\mathrm{L}(\mathrm{M} 1)=\left[\begin{array}{c}
{\left[(0.8) *(0.983)^{3}\right]+\left[\begin{array}{c}
(0.02) \\
*(0.37)^{3}
\end{array}\right]+\left[(0.03) *(0.94)^{3}\right]+} \\
{\left[(0.03) *(0.38)^{3}\right]+\left[(0.03) *(0.35)^{3}\right]+\left[(0.03) *(0.19)^{3}\right]+} \\
{\left[(0.03) *(0.85)^{3}\right]+\left[(0.03) *(0.963)^{3}\right]}
\end{array}\right]^{\frac{1}{3}}
$$

$=0.9375$

Table 14: LSP value based on the OWA

\begin{tabular}{|l|l|}
\hline Web Service & LSP value \\
\hline WS1 & 0.9375 \\
\hline WS2 & 0.8931 \\
\hline WS3 & 0.98571 \\
\hline WS4 & 0.4154 \\
\hline WS5 & 0.9871 \\
\hline
\end{tabular}

\section{Step $5 \quad$ : Ranking of Web Services}

In view of the got LSP esteem, the web services are positioned. The positioned web services are appeared in the accompanying Table 15:

Table 15: Web services ranking

\begin{tabular}{|l|l|l|}
\hline Web Service & LSP value & Rank \\
\hline WS5 & 0.9871 & 1 \\
\hline WS3 & 0.98571 & 2 \\
\hline WS1 & 0.9375 & 3 \\
\hline WS2 & 0.8931 & 4 \\
\hline WS4 & 0.4154 & 5 \\
\hline
\end{tabular}

The web service 5 has the least response time and it is ranked first. Likewise the web service 4 has highest response time and it takes the last rank.

\section{Web Service Selection Using Fuzzy Topsis Method:}

Fuzzy Topsis technique is an out-positioning strategy for different measures dynamic. This strategy is utilized for vector normalization procedure. Coming up next are the different advances associated with the TOPSIS strategy $[13,14]$ :

\section{Step 1 : Determination of Ratings of Decision Makers}

Various decision makers' opinion is collected and the distances between the services are calculated using PIS and NIS based on the consumer preferences. The ratings of decision makers are shown in Table 16. 
Table 16: Ratings of decision makers and corresponding values

\begin{tabular}{|l|l|}
\hline Decision Makers Ratings & Rating Value \\
\hline Very Poor & 1.333 \\
\hline Poor & 3.000 \\
\hline Fair & 5.000 \\
\hline Good & 7.000 \\
\hline Very Good & 8.667 \\
\hline
\end{tabular}

\section{Step 2 : Construct the fuzzy decision matrix (WS x K) and service rating of QoS}

The Decision creators (K) give the rating of each web services (WS) as for the QoS boundaries (Q). Utilizing those models, a WS $x$ K matrix is framed subsequent to gathering the appraisals from $\mathrm{K}$ chiefs for M web services. In the accompanying Table $17 \mathrm{~K}$ and $\mathrm{M}$ are considered as five:

Table 17: Ratings of decision makers for response time

\begin{tabular}{|l|l|l|l|l|l|}
\hline Web services & K1 & K2 & K3 & K4 & K5 \\
\hline WS1 & 5.0 & 8.667 & 7.0 & 8.667 & 8.667 \\
\hline WS2 & 7.0 & 5.0 & 8.667 & 8.667 & 7.0 \\
\hline WS3 & 8.667 & 7.0 & 5.0 & 3.0 & 5.0 \\
\hline WS4 & 5.0 & 7.0 & 5.0 & 7.0 & 3.0 \\
\hline WS5 & 7.0 & 3.0 & 5.0 & 8.667 & 7.0 \\
\hline
\end{tabular}

\section{Step $3 \quad$ : Assign weight of QoS Parameters based on users}

The favored weights given by the clients for the eight QoS standard are accumulated .The weights are given in the accompanying Table 18:

Table 18: User assigns higher weight for response time

\begin{tabular}{|l|l|l|l|l|l|l|l|l|}
\hline QoS Parameter & Q1 & Q2 & Q3 & Q4 & Q5 & Q6 & Q7 & Q8 \\
\hline Weight & 0.8 & 0.02 & 0.03 & 0.03 & 0.03 & 0.03 & 0.03 & 0.03 \\
\hline
\end{tabular}

\section{Step $4 \quad$ : $\quad$ Form the Aggregated Weighted Decision Matrix}

The different ratings given by the decision makers are aggregated and crisp ratings of web services are obtained. This is performed using the Equation 15.

$\mathrm{R}_{\mathrm{ij}}=\frac{\sum_{\mathrm{t}=1}^{\mathrm{k}} \mathrm{r}_{\mathrm{ijt}}}{\mathrm{k}}$

Where $r_{i j t}$ are the ratings given by decision makers with respect to the web services row values (i), quality of services column values (j) and decision makers individual service rating $\mathrm{K}$. The aggregated crisp rating for the first web service is the given below derivation:

$$
\mathrm{R}_{\mathrm{ij}}=\frac{\sum_{\mathrm{t}=1}^{\mathrm{k}} \mathrm{r}_{\mathrm{ijt}}}{\mathrm{k}}=\frac{5.0+8.667+7.0+8.667+8.667}{5}=7.600
$$

The following Table 19 shows the aggregated crisp value for all the web services:

Table 19: Aggregated crisp ratings of web services

\begin{tabular}{|l|l|l|l|l|l|l|l|l|}
\hline & Q1 & Q2 & Q3 & Q4 & Q5 & Q6 & Q7 & Q8 \\
\hline WS1 & 7.600 & 8.334 & 6.200 & 8.334 & 8.667 & 8.334 & 8.667 & 1.4 \\
\hline
\end{tabular}




\begin{tabular}{|l|l|l|l|l|l|l|l|l|}
\hline WS2 & 7.267 & 6.534 & 5.000 & 5.800 & 2.333 & 6.200 & 6.134 & 4.000 \\
\hline WS3 & 5.734 & 4.600 & 5.734 & 7.266 & 4.600 & 4.200 & 2.733 & 6.8 \\
\hline WS4 & 5.4 & 4.6 & 5.4 & 5.8 & 5.4 & 5.0 & 6.2 & 3.8 \\
\hline WS5 & 6.134 & 5.0 & 5.0 & 6.134 & 3.867 & 3.0 & 5.0 & 1.8 \\
\hline
\end{tabular}

\section{Step 5 : Determine the Normalized Decision Matrixes}

The development of choice framework, the information is normalized by Equation 16 for the traits that should be limited and by Equation 17 for the properties that should be expanded.

$$
\begin{aligned}
& S_{i j=} \frac{R_{i j}}{\sqrt{\sum_{i=1}^{m} \frac{1}{R_{i j}}}} \\
& S_{i j}=\frac{R_{i j}}{\sqrt{\sum_{i=1}^{m}\left(R_{i j}\right)^{2}}}
\end{aligned}
$$

Where, $S_{i j}$ is the normalized decision matrix and $R_{i j}$ is the crisp ratings of web services shown in Table 20. For example, response time assigned for the calculation of normalized decision matrixes is given in the below derivation. From the Equation (16) and 18 we get the following result:

$$
\begin{aligned}
& S_{\mathrm{ij}}=\frac{7.6}{\sqrt{\left(\frac{1}{7.6^{2}+8.334^{2}+6.2^{2}+8.334^{2}+8.667^{2}+8.334^{2}+8.667^{2}+1.4^{2}}\right)}}=0.006587 \\
& S_{\mathrm{ij}}=\frac{6.534}{\sqrt{6.534^{2}+5.000^{2}+5.800^{2}+2.333^{2}+6.2^{2}+6.132^{2}+4.000^{2}+7.267^{2}}}=0.463318
\end{aligned}
$$

Similarly, the vector normalization is performed and the normalized decision matrix is shown in the

Table 20.

Table 20: Normalized decision matrixes

\begin{tabular}{|l|l|l|l|l|l|l|l|l|}
\hline & Q1 & Q2 & Q3 & Q4 & Q5 & Q6 & Q7 & Q8 \\
\hline WS1 & 0.006587 & 0.417203 & 0.310389 & 0.417203 & 0.433893 & 0.417203 & 0.433893 & 0.41720 \\
\hline WS2 & 0.009758 & 0.463318 & 0.354577 & 0.411309 & 0.165459 & 0.439675 & 0.434952 & 0.28366 \\
\hline WS3 & 0.012352 & 0.325775 & 0.406043 & 0.514639 & 0.325775 & 0.297446 & 0.193567 & 0.48158 \\
\hline WS4 & 0.013398 & 0.332814 & 0.390695 & 0.419635 & 0.390695 & 0.361754 & 0.448575 & 0.27493 \\
\hline WS5 & 0.013787 & 0.422825 & 0.422825 & 0.518671 & 0.326979 & 0.253695 & 0.422825 & 0.15221 \\
\hline
\end{tabular}

Step $6 \quad$ : Compose the aggregated weighted decision matrix

The following stage is computation of weighted choice matrix. The weighted worth is gotten from the result of components in the normalized choice lattice and fresh weights. The recipe to locate the weighted choice grid is show in the Equation 18.

$\mathrm{v}_{\mathrm{ij}}=\mathrm{W}_{\mathrm{j}} * \mathrm{~S}_{\mathrm{ij}}$

where $\mathrm{V}_{\mathrm{ij}}$ the weighted decision matrix and $\mathrm{W}_{\mathrm{j}}$ is the crisp weights shown in Table 21 . The example of response time based calculation for the following derivation gives the response time decision matrix $\mathrm{v}_{\mathrm{ij}}=0.8 * 0.006587=$ 0.005269. Similarly, the calculated weighted decision matrix is shown in the following Table 21:

Table 21: Weighted decision matrixes 


\begin{tabular}{|l|l|l|l|l|l|l|l|l|}
\hline & Q1 & Q2 & Q3 & Q4 & Q5 & Q6 & Q7 & Q8 \\
\hline WS1 & 0.005269 & 0.008344 & 0.009311 & 0.012516 & 0.013016 & 0.012516 & 0.013016 & 0.00210 \\
\hline WS2 & 0.007807 & 0.009266 & 0.010637 & 0.012339 & 0.004963 & 0.013190 & 0.013048 & 0.00850 \\
\hline WS3 & 0.009881 & 0.006515 & 0.012181 & 0.015439 & 0.009773 & 0.008923 & 0.005807 & 0.01444 \\
\hline WS4 & 0.010718 & 0.006656 & 0.011720 & 0.012589 & 0.011720 & 0.010852 & 0.013457 & 0.00824 \\
\hline WS5 & 0.011030 & 0.008456 & 0.012684 & 0.015560 & 0.009809 & 0.007610 & 0.012684 & 0.00456 \\
\hline
\end{tabular}

Step $7 \quad$ : $\quad$ Compute the fuzzy positive ideal solution and fuzzy negative ideal solution

The subsequent stage is to compute Positive Ideal Solution (PIS) and Negative Ideal Solution (NIS).

PIS $\left(\mathrm{A}^{+}\right)$and the NIS $\left(\mathrm{A}^{-}\right)$can be picked up from the accompanying Equation :

$\mathrm{A}^{+}=\left\{\max v_{\mathrm{ij}}\right\}$

$\mathrm{A}^{-}=\left\{\min v_{\mathrm{ij}}\right\}$

$\mathrm{A}^{+}=\max (0.005269,0.007807,0.009881,0.010718,0.011030)=0.011030$

$\mathrm{A}^{-}=\min (0.005269,0.007807,0.009881,0.010718,0.011030)=0.005269$

Similarly, the PIS and NIS from the weighted decision matrix is shown in the following Table 22:

Table 22: Positive and Negative Index solution

\begin{tabular}{|l|l|l|l|l|l|l|l|l|}
\hline & Q1 & Q2 & Q3 & Q4 & Q5 & Q6 & Q7 & Q8 \\
\hline PIS & 0.011030 & 0.009266 & 0.012684 & 0.015560 & 0.013016 & 0.013190 & 0.013457 & 0.01444 \\
\hline NIS & 0.005269 & 0.006515 & 0.009311 & 0.012339 & 0.004963 & 0.007610 & 0.005807 & 0.00210 \\
\hline
\end{tabular}

\section{Step 8 : Calculate the distance of PIS and NIS}

The following stage is to gauge the separation of every option from the PIS and the NIS individually.

The Euclidean distance is utilized to quantify the separation of every option from $\mathrm{A}^{+}$and $\mathrm{A}^{-}$as follows utilizing the Equation 21 and 22:

$$
\begin{aligned}
& \mathrm{d}_{\mathrm{i}}^{+}=\sqrt{\sum_{\mathrm{j}=1}^{\mathrm{n}}\left(\mathrm{v}_{\mathrm{ij}-\mathrm{v}_{\mathrm{j}}^{+}}\right)^{2}} \\
& \mathrm{~d}_{\mathrm{i}}^{-}=\sqrt{\sum_{\mathrm{j}=1}^{\mathrm{n}\left(\mathrm{v}_{\mathrm{ij}-\mathrm{v}_{\mathrm{j}}^{-}}\right)^{2}}} \\
& \quad \begin{array}{r}
\mathrm{d}_{\mathrm{i}}^{+}=\operatorname{sqrt}\left((0.005269-0.011030)^{2}+(0.008344-0.011030)^{2}+(0.009311-0.011030)^{2}\right. \\
\quad+(0.012516-0.011030)^{2}+(0.013016-0.011030)^{2}+(0.012516-0.011030)^{2} \\
\left.+(0.013016-0.011030)^{2}+(0.00210-0.011030)^{2}\right)=0.014412
\end{array}
\end{aligned}
$$

The distance measured values are shown in the following Table 23.

Table 23: Distance Measure

\begin{tabular}{|l|c|c|}
\hline Web Service & $\mathrm{d}_{\mathrm{i}}^{\mp}$ & $\mathrm{d}_{\mathrm{i}}^{-}$ \\
\hline WS1 & 0.014412 & 0.012011 \\
\hline
\end{tabular}




\begin{tabular}{|l|l|l|}
\hline WS2 & 0.011190 & 0.011848 \\
\hline WS3 & 0.009818 & 0.014709 \\
\hline WS4 & 0.007889 & 0.013712 \\
\hline WS5 & 0.011844 & 0.011642 \\
\hline
\end{tabular}

\section{Step $9 \quad$ : Calculate Relative Closeness Coefficient (RCC):}

Relative Closeness Coefficient (RCC) which is used to find the rank of every service with respect to the user preference services. At last, positioned web services are select and picked the one better help among the quantity of web services. The relative closeness coefficient of the ith elective RCC_i can be registered by the accompanying Equation 23:

$\operatorname{RCC}_{\mathrm{i}}=\frac{\mathrm{d}_{\mathrm{i}}^{-}}{\mathrm{d}_{\mathrm{i}}^{+}+\mathrm{d}_{\mathrm{i}}^{-}}$

The following calculations are used for determining the Relative Closeness Coefficient of every web services which is used to ranking the web services shown in the following Table 24:

$\mathrm{RCC}_{\mathrm{i}}=0.012011 /(.014412+0.012011)=0.4545614$

Table 24: Relative Closeness Coefficient and rank

\begin{tabular}{|l|l|l|}
\hline Web Service & RCC & Rank \\
\hline WS1 & 0.4545614 & 5 \\
\hline WS2 & 0.5142797 & 3 \\
\hline WS3 & 0.5996941 & 2 \\
\hline WS4 & 0.6347851 & 1 \\
\hline WS5 & 0.4956977 & 4 \\
\hline
\end{tabular}

\section{EXPERIMENTAL RESULTS FOR WEB SERVICE SELECTION:}

A contextual analysis can be performed on Health care product Shopping area where a client needs a pertinent help among all services with comparative functionalities. The client can go for non-functional attributes with determination procedures to improve the choice. The accompanying experimentation was finished with some QoS esteems taken from the QWS dataset [16] provided by [1]. A portion of the QoS esteems are made and transfer in fusion registry. The explore was directed utilizing ANOVA just the main Twenty five assistance esteems are considered as appeared in Table A.1 in Appendix

Web service requestor wants best service; it is retrieved by using QoS based service selection. For example, this paper considers twenty five services and forty user preferences. Experimental result for AHP, LSP and Fuzzy methods has shown in Table 25,26,27,28 and 29

The Response time, Throughput combine together group1 and AHP returns the web service (number: 7). In the next group2 (Scalability, Reliability, Availability, Accessibility) of QoS, AHP returns web service 25. In third group (Reputation) AHP returns web service (number: 5). In Fourth group (Cost) AHP returns the web service 9 as shown in table 25 .

Table 25: Experimental result for AHP 


\begin{tabular}{|l|l|l|l|l|}
\hline AHP & Group1 & Group2 & Group3 & Group4 \\
\hline Service Retrieval count & 7 & 25 & 5 & 9 \\
\hline
\end{tabular}

Table 26: Experimental result for LSP combined parameters (single, double, three, four)

\begin{tabular}{|c|c|c|c|c|c|c|c|c|}
\hline \multirow{2}{*}{\begin{tabular}{|l|}
\multicolumn{1}{|c|}{ LSP } \\
Combination of \\
Parameters
\end{tabular}} & \multicolumn{2}{|c|}{ Single Parameter } & \multicolumn{2}{|c|}{ Two Parameter } & \multicolumn{2}{|c|}{ Three Parameter } & \multicolumn{2}{|c|}{ Four Parameter } \\
\hline & $\mathrm{Q} 1=0.8$ & $\begin{array}{l}\text { Other } \\
\text { Parameter } \\
\left(\mathrm{O} \_P\right)<0.2\end{array}$ & $\begin{array}{l}\text { Q1,Q2 } \\
=0.4\end{array}$ & O_P $<0.2$ & $\begin{array}{l}\text { Q1 to Q3 } \\
=0.3\end{array}$ & O_P $<0.1$ & $\begin{array}{l}\text { Q1 to Q4= } \\
0.2\end{array}$ & O_P $<0.2$ \\
\hline Service retrieval count & \multicolumn{2}{|l|}{11} & \multicolumn{2}{|l|}{11} & \multicolumn{2}{|l|}{11} & \multicolumn{2}{|l|}{11} \\
\hline $\begin{array}{l}\text { Combination of } \\
\text { Parameters }\end{array}$ & \multicolumn{2}{|l|}{$\mathrm{Q} 2=0.8$} & \multicolumn{2}{|l|}{$\mathrm{Q} 2, \mathrm{Q} 3=0.4$} & \multicolumn{2}{|c|}{$\mathrm{Q} 2$ to $\mathrm{Q} 4=0.3$} & \multicolumn{2}{|c|}{$\mathrm{Q} 2$ to $\mathrm{Q} 5=0.2$} \\
\hline Service retrieval count & \multicolumn{2}{|l|}{11} & \multicolumn{2}{|l|}{20} & \multicolumn{2}{|l|}{11} & \multicolumn{2}{|l|}{7} \\
\hline $\begin{array}{l}\text { Combination of } \\
\text { Parameters }\end{array}$ & \multicolumn{2}{|l|}{$\mathrm{Q} 3=0.8$} & \multicolumn{2}{|l|}{$\mathrm{Q} 3, \mathrm{Q} 4=0.4$} & \multicolumn{2}{|c|}{$\mathrm{Q} 3$ to $\mathrm{Q} 5=0.3$} & \multicolumn{2}{|c|}{$\mathrm{Q} 3$ to $\mathrm{Q} 6=0.2$} \\
\hline Service retrieval count & \multicolumn{2}{|l|}{10} & \multicolumn{2}{|l|}{25} & \multicolumn{2}{|l|}{3} & \multicolumn{2}{|l|}{3} \\
\hline $\begin{array}{l}\text { Combination of } \\
\text { Parameters }\end{array}$ & \multicolumn{2}{|l|}{$\mathrm{Q} 4=0.8$} & \multicolumn{2}{|l|}{$\mathrm{Q} 4, \mathrm{Q} 5=0.4$} & \multicolumn{2}{|c|}{$\mathrm{Q} 4$ to $\mathrm{Q} 6=0.3$} & \multicolumn{2}{|c|}{$\mathrm{Q} 4$ to $\mathrm{Q} 7=0.2$} \\
\hline Service retrieval count & \multicolumn{2}{|l|}{11} & \multicolumn{2}{|l|}{3} & \multicolumn{2}{|l|}{3} & \multicolumn{2}{|l|}{3} \\
\hline $\begin{array}{l}\text { Combination of } \\
\text { Parameters }\end{array}$ & \multicolumn{2}{|l|}{$\mathrm{Q} 5=0.8$} & \multicolumn{2}{|l|}{$\mathrm{Q} 5, \mathrm{Q} 6=0.4$} & \multicolumn{2}{|c|}{$\mathrm{Q} 5$ to $\mathrm{Q} 7=0.3$} & Q5 to $\mathrm{Q} 8=$ & 0.2 \\
\hline Service retrieval count & 23 & & & & 7 & & & \\
\hline $\begin{array}{l}\text { Combination of } \\
\text { Parameters }\end{array}$ & $\mathrm{Q} 6=0.8$ & & 4 & & $\mathrm{Q} 6$ to $\mathrm{Q} 8$ & & & \\
\hline Service retrieval count & 23 & & & & & & & \\
\hline $\begin{array}{l}\text { Combination of } \\
\text { Parameters }\end{array}$ & $\mathrm{Q} 7=0.8$ & & $\mathrm{Q} 7, \mathrm{Q} 8=0.4$ & & & & 23 & \\
\hline Service retrieval count & 20 & & & & 10 & & & \\
\hline $\begin{array}{l}\text { Combination of } \\
\text { Parameters }\end{array}$ & $\mathrm{Q} 8=0.8$ & & 7 & & & & & \\
\hline Service retrieval count & 11 & & & & & & & \\
\hline
\end{tabular}

Table 27: Experimental result for LSP combined parameters (five, six, seven, and eight)

\begin{tabular}{|l|l|l|l|l|l|l|l|}
\hline LSP \\
\hline \# parameters & \multicolumn{2}{|l|}{ Five Parameters } & \multicolumn{2}{l|}{ Six Parameters } & \multicolumn{2}{l|}{ Seven Parameters } & Eight Parameters \\
\hline $\begin{array}{l}\text { Combination of } \\
\text { Parameters }\end{array}$ & Q1 to & Q5 $=0.15$ & O_P $<0.25$ & Q1 to Q6 \\
$=0.15$ & O_P $<0.1$ & $\begin{array}{l}\text { Q1 to Q7 } \\
=0.13\end{array}$ & O_P $<0.1$ & Q1 to Q8 $=0.125$ \\
\hline $\begin{array}{l}\text { Service retrieval } \\
\text { count }\end{array}$ & $\mathbf{1 1}$ & $\mathbf{1 1}$ & $\mathbf{1 1}$ & $\mathbf{1 1}$ \\
\hline Combination of & Q2 to Q6=0.15 & Q2 to Q7 $=0.15$ & Q2 to Q8 $=.13$ & \\
\hline
\end{tabular}




\begin{tabular}{|c|c|c|c|c|}
\hline Parameters & & & & \\
\hline $\begin{array}{l}\text { Service retrieval } \\
\text { count }\end{array}$ & 3 & 4 & 11 & \\
\hline \begin{tabular}{|l} 
Combination of \\
Parameters
\end{tabular} & $\mathrm{Q} 3$ to $\mathrm{Q} 7=0.15$ & $\mathrm{Q} 3$ to $\mathrm{Q} 8=.15$ & & \\
\hline \begin{tabular}{|l} 
Service retrieval \\
count
\end{tabular} & 3 & & & \\
\hline \begin{tabular}{|l} 
Combination of \\
Parameters
\end{tabular} & $\mathrm{Q} 4$ to $\mathrm{Q} 8=0.15$ & 3 & & \\
\hline $\begin{array}{l}\text { Service retrieval } \\
\text { count }\end{array}$ & 23 & & & \\
\hline
\end{tabular}

Table 28: Experimental result for Fuzzy Topsis combined parameters (single, double, three, four)

\begin{tabular}{|c|c|c|c|c|c|c|c|c|c|}
\hline \multicolumn{10}{|c|}{ FUZZY TOPSIS } \\
\hline & \multirow{2}{*}{\begin{tabular}{|l|} 
No.of Parameters \\
Combination of \\
Parameters
\end{tabular}} & \multicolumn{2}{|c|}{ Single Parameter } & \multicolumn{2}{|c|}{ Two Parameters } & \multicolumn{2}{|c|}{ Three Parameters } & \multicolumn{2}{|c|}{ Four Parameters } \\
\hline & & $\mathrm{Q} 1=0.8$ & $\begin{array}{l}\text { Other } \\
\text { Parameter } \\
\left(\mathrm{O} \_\mathrm{P}\right)<0.8\end{array}$ & $\begin{array}{l}\mathrm{Q} 1, \mathrm{Q} 2 \\
=0.4\end{array}$ & O_P $<0.4$ & $\begin{array}{l}\text { Q1 to } \mathrm{Q} 3 \\
=0.3\end{array}$ & O_P $<0.3$ & $\begin{array}{l}\text { Q1 to } \\
Q 4=0.2\end{array}$ & O_P $<0.2$ \\
\hline & $\begin{array}{l}\text { Service retrieval } \\
\text { count }\end{array}$ & \multicolumn{2}{|l|}{8} & \multicolumn{2}{|l|}{8} & \multicolumn{2}{|l|}{8} & \multicolumn{2}{|l|}{8} \\
\hline & $\begin{array}{l}\text { Combination of } \\
\text { Parameters }\end{array}$ & \multicolumn{2}{|l|}{$\mathrm{Q} 2=0.8$} & \multicolumn{2}{|l|}{$\mathrm{Q} 2, \mathrm{Q} 3=0.4$} & \multicolumn{2}{|l|}{$\begin{array}{l}\mathrm{Q} 2 \text { to } \mathrm{Q} 4 \\
=0.3\end{array}$} & \multicolumn{2}{|c|}{$\mathrm{Q} 2$ to $\mathrm{Q} 5=0.2$} \\
\hline & $\begin{array}{l}\text { Service retrieval } \\
\text { count }\end{array}$ & \multicolumn{2}{|l|}{11} & \multicolumn{2}{|l|}{11} & \multicolumn{2}{|l|}{11} & \multicolumn{2}{|l|}{8} \\
\hline & $\begin{array}{l}\text { Combination of } \\
\text { Parameters }\end{array}$ & \multicolumn{2}{|l|}{$\mathrm{Q} 3=0.8$} & \multicolumn{2}{|l|}{$\mathrm{Q} 3, \mathrm{Q} 4=0.4$} & \multicolumn{2}{|l|}{$\begin{array}{l}\mathrm{Q} 3 \text { to } \mathrm{Q} 5 \\
=0.3\end{array}$} & \multicolumn{2}{|c|}{ Q3to $Q 6=0.2$} \\
\hline & $\begin{array}{c}\text { Service retrieval } \\
\text { count }\end{array}$ & \multicolumn{2}{|l|}{5} & \multicolumn{2}{|l|}{20} & \multicolumn{2}{|l|}{3} & \multicolumn{2}{|l|}{11} \\
\hline & $\begin{array}{c}\text { Combination of } \\
\text { Parameters }\end{array}$ & \multicolumn{2}{|l|}{$\mathrm{Q} 4=0.8$} & \multicolumn{2}{|l|}{$\mathrm{Q} 4, \mathrm{Q} 5=0.4$} & \multicolumn{2}{|l|}{$\begin{array}{l}\text { Q4 to Q6 } \\
=0.3\end{array}$} & \multicolumn{2}{|c|}{$\mathrm{Q} 4$ to $\mathrm{Q} 7=0.2$} \\
\hline & $\begin{array}{c}\text { Service retrieval } \\
\text { count }\end{array}$ & \multicolumn{2}{|l|}{11} & \multicolumn{2}{|l|}{11} & \multicolumn{2}{|l|}{5} & \multicolumn{2}{|l|}{11} \\
\hline & $\begin{array}{c}\text { Combination of } \\
\text { Parameters }\end{array}$ & \multicolumn{2}{|l|}{$\mathrm{Q} 5=0.8$} & \multicolumn{2}{|l|}{$\mathrm{Q} 5, \mathrm{Q} 6=0.4$} & \multicolumn{2}{|l|}{$\begin{array}{l}\text { Q5 to Q7 } \\
=0.3\end{array}$} & Q5 to $\mathrm{Q} 8$ & $=0.2$ \\
\hline 䓂 & $\begin{array}{c}\text { Service retrieval } \\
\text { count }\end{array}$ & 11 & & & & 11 & & & \\
\hline$\stackrel{\tilde{z}}{\stackrel{\tilde{Z}}{E}}$ & $\begin{array}{c}\text { Combination of } \\
\text { Parameters }\end{array}$ & Q6 $=0.8$ & & 11 & & $\begin{array}{l}\text { Q6 to Q8 } \\
=0.3\end{array}$ & & 7 & \\
\hline$\sum_{0}^{0}$ & $\begin{array}{c}\text { Combination of } \\
\text { Parameters }\end{array}$ & 6 & & & & 7 & & & \\
\hline
\end{tabular}




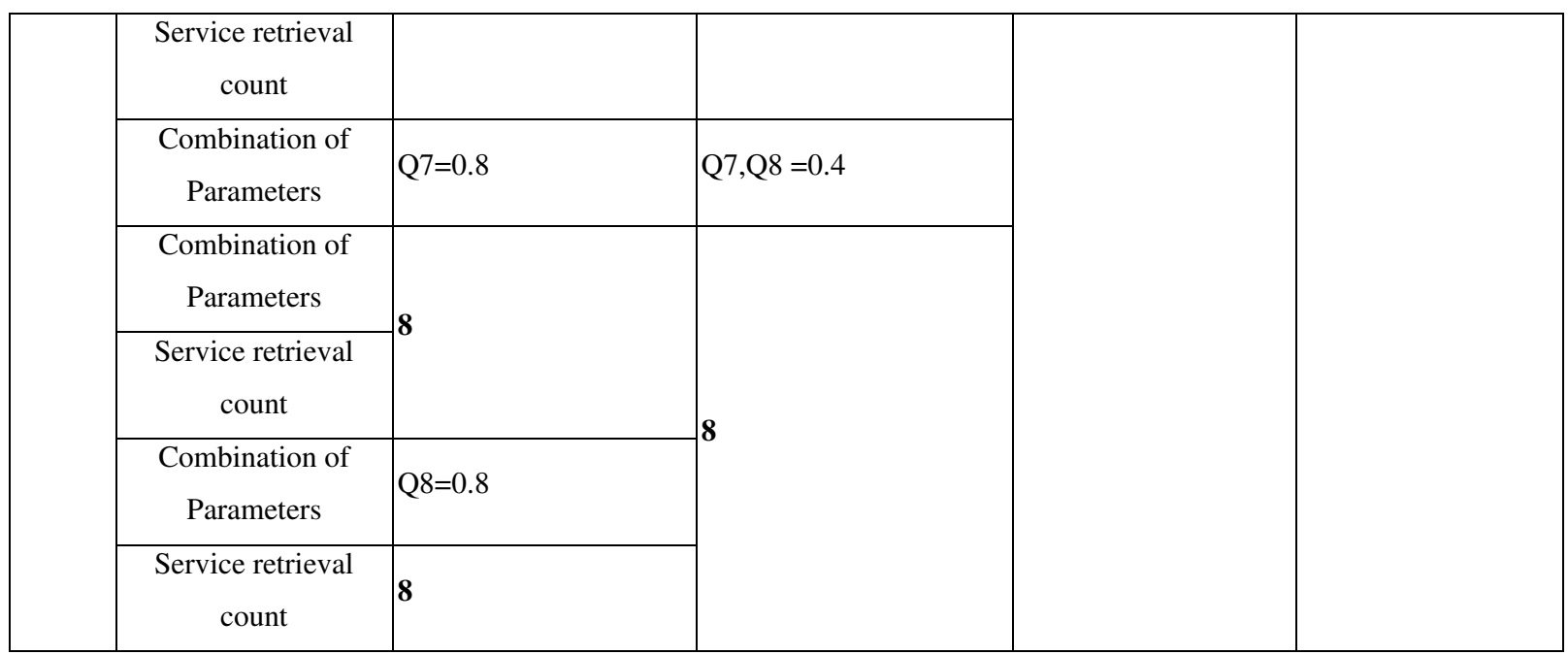

Table 29: Experimental result for Fuzzy Topsis combined parameters (five, Six, Seven, Eight)

\begin{tabular}{|c|c|c|c|c|c|c|c|c|c|}
\hline & \multicolumn{9}{|c|}{ FUZZY TOPSIS } \\
\hline & \multirow{2}{*}{\begin{tabular}{|l|} 
No.of Parameters \\
Combination of \\
Parameters
\end{tabular}} & \multicolumn{2}{|c|}{$\begin{array}{c}\text { Five } \\
\text { Parameters }\end{array}$} & \multicolumn{2}{|c|}{ Six Parameters } & \multicolumn{2}{|c|}{ Seven Parameters } & \multicolumn{2}{|c|}{ Eight Parameters } \\
\hline \multirow{8}{*}{ 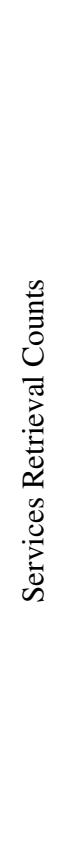 } & & $\begin{array}{l}\mathrm{Q} 1 \text { to } \\
\mathrm{Q} 5=0.2\end{array}$ & O_P $<0.2$ & $\begin{array}{l}\mathrm{Q} 1 \text { to } \mathrm{Q} 6 \\
=0.15\end{array}$ & O_P $<0.15$ & $\begin{array}{l}\text { Q1 to Q7 } \\
=0.14\end{array}$ & O_P $<0.14$ & $\begin{array}{l}\mathrm{Q} 1 \text { to } \mathrm{Q} 8 \\
=0.13\end{array}$ & O_P $<0.13$ \\
\hline & $\begin{array}{l}\text { Service retrieval } \\
\text { count }\end{array}$ & 7 & & \multicolumn{2}{|l|}{8} & \multicolumn{2}{|l|}{7} & \multirow{7}{*}{\multicolumn{2}{|c|}{8}} \\
\hline & $\begin{array}{l}\text { Combination of } \\
\text { Parameters }\end{array}$ & $\mathrm{Q} 2$ to $\mathrm{Q}$ & & Q2 to Q7 = & .15 & $\mathrm{Q} 2$ to $\mathrm{Q} 8=$ & & & \\
\hline & $\begin{array}{l}\text { Service retrieval } \\
\text { count }\end{array}$ & 11 & & 11 & & \multirow{5}{*}{\multicolumn{2}{|c|}{7}} & & \\
\hline & $\begin{array}{l}\text { Combination of } \\
\text { Parameters }\end{array}$ & Q3 to $Q$ & & Q3 to $\mathrm{Q} 8=$ & & & & & \\
\hline & $\begin{array}{l}\text { Service retrieval } \\
\text { count }\end{array}$ & 11 & & \multirow{3}{*}{\multicolumn{2}{|c|}{11}} & & & & \\
\hline & $\begin{array}{l}\text { Combination of } \\
\text { Parameters }\end{array}$ & \multicolumn{2}{|c|}{$\mathrm{Q} 4$ to $\mathrm{Q} 8=0.2$} & & & & & & \\
\hline & $\begin{array}{l}\text { Service retrieval } \\
\text { count }\end{array}$ & \multicolumn{2}{|l|}{11} & & & & & & \\
\hline
\end{tabular}

The above Table 25,26,27,28 and 29 shows trial result for AHP, LSP and Fuzzy Topsis strategies. The shoppers have the purchasing inclinations like Response time, Throughput, Reliability, Scalability and Availability of health care product. Thusly, the client needs to demand for health care product shopping administrations alongside their inclinations. The above Table 29 shows the client inclination for five boundaries in particular Response time (Q1), Throughput (Q2), Reliability (Q3), Scalability (Q4), Availability (Q5) at that point greatest equivalent weight is 
given to that five boundaries and least weight is given to all different boundaries which is equivalent to the unit esteem one.

For the above weights, Service number 7 is recovered. Response time (Q1) is less and Throughput (Q2), Reliability (Q3), Scalability (Q4), Availability (Q5) is high for service 7. Thus, client weights are given to other mix of QoS boundaries. The acquired outcomes can be tried by utilizing ANOVA. It is utilized to investigation the presentation of every one of determination strategies. The accompanying segment gives Statistical examination esteems to three strategies.

\section{DATA ANALYSIS}

To think about the aftereffects of both the determination techniques examination of fluctuation (ANOVA) and post hoc tests are utilized. ANOVA is a measurable method to think about informational indexes. The F proportion is the likelihood data created by an ANOVA. It is chiefly used to assess contrasts between informational collections. In this suggestion framework, this ANOVA instrument is utilized to assess contrasts between choice strategies. In ANOVA, the dismissal rule is to dismiss the theory if F-test measurement is greater than F-basic incentive from the table. This was refined as following speculation.

H0: The methods for all the gatherings are equivalent. H1: Not all the methods are equivalent Coming up next are the Computational formulae for ANOVA test

1. $\mathrm{df}($ rows $)=\mathrm{n}-1, \mathrm{df}($ sections $)=\mathrm{n}-1$ and $\mathrm{df}($ rows $)+\mathrm{df}($ columns $)+\mathrm{df}($ error $)=\mathrm{df}($ total $), \mathrm{df}($ total $)=\mathrm{N}-1$

2. $\quad \mathrm{SS}($ total $)=\sum\left(X_{i j}-\bar{X}\right)^{2}$,

$\mathrm{SS}($ segment and line $)=\mathrm{n} \sum\left(X_{j}-\bar{X}\right)^{2}$ and SS $($ Error $)=\sum\left(X_{i j}-\bar{X}_{J}\right)^{2}$,

$\mathrm{SS}($ Error $)=\mathrm{SS}($ total $)-\mathrm{SS}($ section$)-\mathrm{SS}($ line $))$

3. $\mathrm{MS}($ line $))=\frac{s s(\text { line })}{d f(\text { line })}, \mathrm{MS}($ column $)=\frac{s s(\text { segment })}{d f(\text { segment })}, \mathrm{MS}($ error $)=\frac{s s(\text { error })}{d f(\text { error })}$

4. $\mathrm{F}($ segment $)=\frac{m s(\text { segment })}{m s(\text { error })}, \mathrm{F}($ row $)=\frac{m s(\text { line })}{m s(\text { error })}$

Where,

Error - the variety or unexplained arbitrary blunder, Total - the complete variety in the information, SS - the aggregate of squares because of the source, $\mathrm{df}$ - the degrees of opportunity in the source, MS - the mean whole of squares because of the source, F - The F-measurement, P - The P esteem, n-all out number of perception absolute qualities, $\mathrm{X}_{\mathrm{j}}=$ group mean, $\overline{\mathrm{X}}=$ grand mean, $\mathrm{X}_{\mathrm{ij}}=$ particular data values. The accompanying outcomes return by the ANOVA in Table 30 utilizing above formula.

At the point when the information for each assistance was thought of, $\mathrm{F}<\mathrm{F}$ crit and subsequently theory turns out to be valid. It implies that there is no huge distinction when the services with contrast in quality of service. Though when the information for every technique was thought of, F > F crit and the dismissal rule can be applied to dismiss the invalid theory. It implies that there is a noteworthy distinction when the techniques used to rank the web services are unique. At any rate one of the methods is unique. Nonetheless, the ANOVA doesn't tell where the distinction lies. We need a t-Test [15] to test each match of mean

Table 30.Two way ANOVA result table 


\begin{tabular}{|c|c|c|c|c|c|c|}
\hline \multicolumn{7}{|c|}{ ANOVA } \\
\hline Source of Variation & SS & $\mathrm{Df}$ & MS & $\mathrm{F}$ & P-Value & F crit \\
\hline Rows & 1.263472 & 24 & 0.052645 & 2.493678 & 0.003508 & 1.74635 \\
\hline Columns & 8.875541 & 2 & 4.43777 & 210.2088 & $1.8 \mathrm{E}-24$ & 3.19072 \\
\hline Error & 1.01334 & 48 & 0.021111 & & & \\
\hline Total & 11.15235 & 74 & & & & \\
\hline
\end{tabular}

Above table 30, F proportion esteem $=2.493678$ and $\mathrm{F}$ crit value $=1.74635$. Here, $\mathrm{F}$ proportion $>\mathrm{F}$ crit. Hence, the two determination strategies are measurably extraordinary. To discover which determination strategy is best post hoc test is utilized

\section{Post-hoc analysis}

A two-followed test was utilized to recognize if either set of results may be better. On the off chance that $\mid t-$ stat| > t-crit, we reject the invalid speculation that implies are same, and close the contrast between the calculations is huge.

A two-followed test was utilized to recognize if either set of results may be better. The recipe for a matched t-test is determined in the accompanying Equation.

$$
t=\frac{\sum d}{\sqrt{\frac{n\left[\sum d^{2}\right]-(\Sigma d)^{2}}{n-1}}}
$$

The numerator of the recipe is the entirety of the distinctions (for example the aggregate of d). The denominator of the recipe peruses as:

The square base of the accompanying: $\mathrm{n}$ times the entirety of the distinctions squared short the aggregate of the squared contrasts, all over n-1.

1. The sum of the squared differences: $\sum \mathrm{d}^{2}$ implies take every distinction thus, square it, and include each one of those squared numbers.

2. The sum of the differences squared: $\left(\sum \mathrm{d}\right)^{2}$ implies include all the distinctions and square the outcome If $|t-s t a t|>t$-crit, we reject the null hypothesis that means are same, and conclude the difference between the algorithms is significant.

On the off chance that $\mid \mathrm{t}$-stat $\mid>\mathrm{t}$-crit, we reject the invalid theory that implies are same, and finish up the contrast between the calculations is huge

Table 31: Paired T-test

\begin{tabular}{|c|c|c|c|c|}
\hline Pair & Set1 & Set2 & P(T, <=t) & Confidence \\
\hline 1 & AHP & LSP & $\mathbf{0 . 0 1 8 \%}$ & $98.76 \%$ \\
\hline 2 & LSP & FUZZY & $\mathbf{6 . 2 3 3 \%}$ & $\mathbf{9 4 . 1 1 \%}$ \\
\hline
\end{tabular}




\begin{tabular}{|l|l|l|l|l|}
\hline 3 & AHP & FUZZY & $\mathbf{2 0 . 2 7 5 \%}$ & $\mathbf{8 1 . 4 \%}$ \\
\hline
\end{tabular}

In view of the Table 31, AHP and LSP are not similarly acceptable; LSP and Fuzzy are similarly acceptable; AHP and Fuzzy are similarly acceptable. As Fuzzy is similarly acceptable consistently it outflanks the other two calculations

\section{DISCUSSION AND CONCLUSION}

This paper evaluates different strategies accessible for positioning the web services dependent on the quality of services boundaries. Explicitly three strategies specifically AHP, LSP and Fuzzy Topsis were executed and the outcomes were appeared in the past segment. One significant inquiry is whether any of these outcome sets is superior to any of the others. First ANOVA test was directed to check whether there is a variety among the outcomes created by the three strategies. Next T-test for combined methods was directed to locate the best strategy. It tends to be closed dependent on ANOVA test, that the change in QoS doesn't show any noteworthy differences and speculation isn't dismissed. While when the strategy was changed shows noteworthy fluctuations and speculation is dismissed. In light of the post-hoc examination Fuzzy Topsis strategy is best determination technique when contrasted and other two strategies

\section{Declarations}

Funding : Not Applicable

Conflicts of interest/Competing interests: No Conflict of Interest

Availability of data and material: Not Applicable Code availability : Not Applicable

Authors' contributions: All authors equally Contributed.

\section{REFERENCES}

1. Al-Masri .E, Mahmoud.Q.H(2007), "QoS-based Discovery and Ranking of Web Services", in Proceedings of the 16th International Conference on Computer Communications and Networks, Honolulu, HI, pp. 529 534.

2. Bian,WU \& Xincai, WU (2010), 'A QoS-aware Method for Web Services Discovery', Journal of Geographic Information System, vol.2, pp.40-44.

3. Buvanesvari, R, Prasath, V \& SanofarNisha H, (2013), 'A Review of Fuzzy Based QoS Web Service Discovery', International Journal of Advanced Networking and Applications, vol.4, no. 5, pp. 1752-1759. 
4. Chi-Chun Lo \& Ding-Yuan Chen (2010), 'Service Selection Based on Fuzzy Topsis Method', IEEE 24th International Conference on Advanced Information Networking and Applications Workshops (WAINA), pp. 367-372

5. Demian Antony, D, Mello \& Ananthanarayana, VS 2008, 'Semantic Web Service Selection Based on Service Provider's Business Offerings', IJSSST, vol. 10, no. 2, pp.1473-8031.

6. Hong Qing,Yu, \& Stephan Reiff-Marganiec 2007, 'A Method for Automated Web Service Selection', Interaction and Context Based Technologies for Collaborative Teams, project. IST-2006-034718.

7. Manoharan .R, Archana .A and Siddhika Nitin Cowlagi (2011), Hybrid Web Services Ranking Algorithm, International Journal of Computer Science Issues(IJCSI), Vol. 8, Issue 3, No. 2.

8. Maheswari,S,Dr. Karpagam. G.R(2011).QoS based efficient web service selection. European Journal of Scientific Research; ISSN 1450-216X Vol.66 No.3, pp. 428-440.

9. Maheswari S., Dr. Karpagam G.R (2013),"Applying Logical Scoring Preference Method for Semantic Web Service Selection" International Journal of Computer Applications (0975 - 8887) Volume 65- No.19.

10. Maheswari S., Dr. Karpagam G.R, S Manasaa (2014), "Design Of Standardization Engine for Semantic Web Service Selection”, Journal of Theoretical and Applied Information Technology. Vol. 66 No.17.

11. Mamat.N.J.Z, Daniel .J.K (2007) ,Statistical analyses on time complexity and rank consistency between singular value decomposition and the duality approach in AHP: A case study of faculty member selection, Mathematical and Computer Modeling 1099-1106.

12. Maheswari, .S, Dr. Karpagam,G.R (2015) Enhancing Fuzzy Topsis for Web Service Selection, International Journal of Computer Applications in Technology, Inderscience,Vol. 51, Issue.4:Pages.344351.

13. Melih Yucesan (2019) An Integrated Best-Worst and Interval Type-2 Fuzzy TOPSIS Methodology for Green Supplier Selection, Mathematics 2019, 7, 182; doi:10.3390/math7020182

14. Neerja Negi, Satish Chandra (2019), Efficient Selection of QoS Based Web Services using Modified TOPSIS Method, International Journal of Recent Technology and Engineering (IJRTE) ISSN: 2277-3878, Volume-8 Issue-2.

15. Nikolaos Pandis (2016),Two-way analysis of variance, American Journal of Orthodontics and Dentofacial Orthopedics Volume 149, Issue 1, Pages 137-139

16. QWS Datasets. http://www.uoguelph.ca/ mahmoud/qws/index.html.

17. Suganyakala.R, Aarthilakshmi.M, Dr.Karpagam.G.R, Maheswari.S (2011), Ontology Based QoS Driven Web Service Discovery.IJCSI International Journal of Computer Science Issues, Vol. 8, Issue 4, No 1, ISSN (Online): 1694-0814, PP.191-198. 
18. Sathya.M, Swarnamugi.M, Dhavachelvan.P, Sureshkumar.G (2010), "Evaluation of QoS Based Webservice Selection Techniques for Service Composition", International Journal of Software Engineering (IJSE), Volume (1): Issue (5)

19. Surendiran.B,Vadivel.A(2011),Feature Selection using Stepwise ANOVA Discriminate Analysis for Mammogram Mass Classification,ACEEE Int. J. on Signal \& Image Processing, Vol. 02, No. 01.

20. Tajudeen Adeyemi Ajao, Safaai-Deris (2013) Optimal Web Service Selection with Consideration for User's Preferences International Journal of Computer Science Issues(IJCSI), Vol. 10, Issue 2, No 3.

21. Tae Kyun Kim (2017), Understanding one-way ANOVA using conceptual figures, Korean Journal of Anesthesiology, VOL. 70, NO. 1.

22. Xi Chen, Zibin Zheng, Qi Yu, \& Michael R Lyu 2014, 'Web service recommendation via exploiting location and qos information', IEEE Transactions On Parallel And Distributed Systems, vol. 25, no. 7.

23. Yuan Han , Zhonghui Wang 2020 , “Application of AHP to Road Selection”, International Journal of GeoInformation, Vol. 9,no. 86. 
Figures

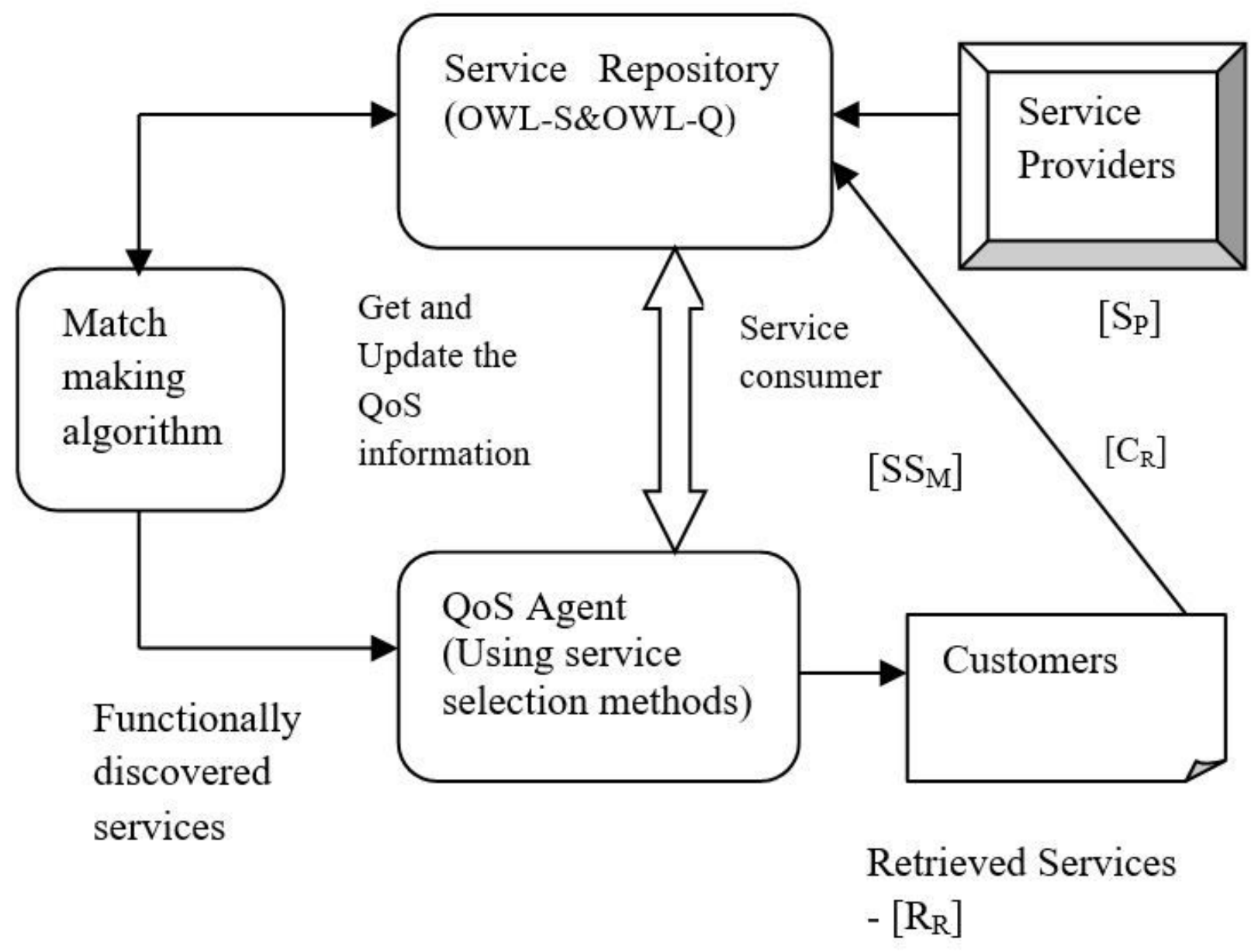

Figure 1

Semantic Web Service Selection Framework 